\title{
Vinorelbine Tartrate
}

National Cancer Institute

\section{Source}

National Cancer Institute. Vinorelbine Tartrate. NCI Thesaurus. Code C1395.

The ditartrate salt of a semisynthetic vinca alkaloid derived from the leaves of the periwinkle plant (Vinca rosea) with antineoplastic properties. Vinorelbine binds to tubulin, thereby inhibiting tubulin polymerization into microtubules and spindle formation and resulting in apoptosis of susceptible cancer cells. Inhibition of mitotic microtubules correlates with antitumor activity, whereas inhibition of axonal microtubules seems to correlate with vinorelbine's neurotoxicity. Compared to related vinca alkaloids, vinorelbine is more selective ag ainst mitotic than axonal microtubules in vitro, which may account for its decreased neurotoxicity. This agent is also a radiation-sensitizing agent. ( $\mathrm{NCl04)}$ 